\title{
A TEMÁTICA AMBIENTAL NO ENSINO SUPERIOR: A CONTRIBUIÇÃO MULTIDISCIPLINAR DA ENGENHARIA AMBIENTAL FACE À BUSCA PELA SUSTENTABILIDADE
}

\section{THE ENVIRONMENTAL ISSUES IN HIGHER EDUCATION: THE MULTIDISCIPLINARY CONTRIBUTION OF ENVIRONMENTAL ENGINEERING FACE TO NEEDED FOR SUSTAINABILITY}

\section{Gláucia Cardoso de Souza ${ }^{1}$; Geraldo Milioli ${ }^{2}$}

${ }^{1}$ Instituto Federal de Educação, Ciência e Tecnologia do Rio Grande do Sul (IFRS), Câmpus Feliz

E-mail: gaudesouza@yahoo.com.br

${ }^{2}$ Universidade do Extremo Sul Catarinense (UNESC)

E-mail: geramil@unesc.net

\begin{abstract}
RESUMO
A questão ambiental começou a ser tratada pelas universidades a partir dos anos 1960, embora, de forma bastante departamentalizada por alguns cursos de graduação. Na década de 1990, houve uma verdadeira explosão de cursos superiores ligados à referida área, com as mais variadas titulações e atribuições. O número de cursos superiores na área ambiental elevou-se de 284 em 2004 para 610 em 2011, com destaque para a área das engenharias com interface em meio ambiente. Neste cenário, a engenharia ambiental surge em 1992, baseada na integração entre algumas linhas de pesquisa e, consequentemente, na necessidade de uma cooperação multidisciplinar. Desse modo, o presente trabalho, com o objetivo de analisar a contribuição da engenharia ambiental enquanto uma ciência emergente no bojo da crise socioambiental, apresenta uma revisão bibliográfica que parte de uma retrospectiva da inserção da temática ambiental nas instituições de ensino superior, passa pelo surgimento da engenharia ambiental no cenário internacional e nacional e culmina com a contribuição específica desta ciência no tocante à discussão multidisciplinar e à busca pela sustentabilidade. Complementarmente, fez-se uma pesquisa junto ao Instituto Nacional de Estudos e Pesquisas Educacionais Anísio Teixeira (INEP) com a finalidade de analisar a evolução dessa área ao longo dos anos. Ao final de 2013, verificou-se o registro de 702 cursos ligados à área ambiental entre cursos de graduação (351), tecnológicos (343) e sequenciais (8).

Palavras-chave: Meio Ambiente. Ensino Superior. Engenharia Ambiental. Multidisciplinaridade.
\end{abstract}

\begin{abstract}
Environmental issues began to be addressed by universities from the 60s, however, quite so departmentalized by traditional undergraduate courses. In the 90s there was an explosion of higher education courses related to that area with varied titles and assignments. The number of higher
\end{abstract}


education courses in the environmental area increased from 284 in 2004 to 610 in 2011, particularly in the area of engineering interface with the environment. In this scenario, environmental engineering arises in 1992, based on the integration between some lines of research and, consequently, multidisciplinary cooperation. Thus, the present study aimed to examine the contribution of environmental engineering as an emerging science in the wake of the environmental crisis presents a literature review that part of the integration of environmental issues in higher education and contextualizes the contribution of environmental engineering from a global and national scene. Additionally, there was a survey from the National Institute for Educational Studies Teixeira (INEP) in order to analyze the development of this area over the years. At the end of 2013, there was the record of 702 courses: undergraduate (351), technological (343) and sequential (8).

Keywords: Environmental. Higher Education. Environmental Engineering. Multidisciplinary.

\section{INTRODUÇÃO}

A questão ambiental e a consequente demanda por soluções científicas e técnicas eram tratadas, nas décadas de 1970 e 1980, de forma departamentalizada pelas instituições de ensino superior, por meio de disciplinas isoladas na grade curricular de alguns cursos: engenharia civil, biologia e geografia. As referências à temática ambiental, na década de 1980, estavam vinculadas, principalmente, aos departamentos de química, biologia e engenharia sanitária (BURSZTYN, 1999).

Diante das limitações dos cursos tradicionais e da necessidade de uma capacitação que não se restringisse exclusivamente à aplicação de técnicas ou conceitos isolados, a década de 1990 se caracterizou pela abertura de cursos na área de meio ambiente com as mais variadas denominações e atribuições (LEAL FILHO, 1999; REIS et al., 2005).

Cita-se, entre os aspectos que motivaram a abertura de cursos para o tratamento da problemática ambiental, o cumprimento das exigências inerentes à legislação ambiental, a pressão da sociedade - especialmente dos movimentos ambientalistas por empreendimentos menos degradadores -, a obrigação implícita de grandes empresas possuírem sistemas de gestão ambiental para manterem relações comerciais com o mercado externo, além da complexidade da temática ambiental e da necessidade de novas tecnologias para a resolução de tais problemas (LEAL FILHO, 1999; REIS et al., 2005).

No universo das engenharias com interface em meio ambiente, a engenharia ambiental é um dos cursos que mais cresceu. Esta área do conhecimento científico, cujo primeiro curso no país remonta ao ano de 1992, caracteriza-se, basicamente, pelo estudo e emprego de técnicas que possibilitam a intervenção eficiente sobre os processos ecológicos, através de uma compreensão integrada do meio ambiente.

Diante desta necessidade de profissionais com capacitação mais abrangente e multidisciplinar em meio ambiente, o presente trabalho, com o objetivo de analisar a contribuição da engenharia ambiental, apresenta uma revisão bibliográfica que parte de uma retrospectiva da inserção da temática ambiental nas instituições de ensino superior. Na sequência, aborda o surgimento desse curso no cenário internacional e nacional e culmina com a contribuição específica dessa ciência, no tocante à discussão multidisciplinar e à busca pela sustentabilidade.

Complementarmente, fez-se uma pesquisa junto ao Instituto Nacional de Estudos e Pesquisas Educacionais Anísio Teixeira (INEP) com a finalidade de analisar a evolução da respectiva área ao longo dos anos. Adotou-se como critério, a seleção de cursos que possuem em sua nomenclatura as palavras: Ambiental, Ambientais ou o termo Meio Ambiente.

Desse modo, o artigo se divide, basicamente, em duas seções: "A temática ambiental e o ensino superior" e "A emergência da engenharia ambiental face à busca pela sustentabilidade". Os 
dados referentes à evolução dos cursos de meio ambiente junto ao banco de dados do INEP encontram-se no final da primeira seção.

\section{A TEMÁTICA AMBIENTAL E O ENSINO SUPERIOR}

De acordo com Bursztyn (1999), a aproximação das instituições de ensino superior com o tema desenvolvimento sustentável não é tão recente quanto a consagração de seu conceito. A partir dos anos 1960, proliferavam-se alertas vindos das universidades, influenciados pelo movimento ambientalista, e relacionados à insensatez do modo como o avanço das ciências vinha se transformando em tecnologias e processos produtivos extremamente degradantes. Na época, as principais contribuições foram: Silent Spring (Primavera Silenciosa, 1962), de Rachel Carson e The Tragedy of the Commons (Tragédia dos Comuns, 1968), de Garret Hardin, respectivamente, na área das ciências agrárias e da biologia (HARDIN, 1968). Já nos anos 1970 as preocupações se voltam também para as ciências econômicas, com o relatório produzido pelo Clube de Roma, que será discutido mais à frente (MEADOWS, 1973).

Ressalta-se que a publicação de Rachel Carson é considerada um clássico do ambientalismo contemporâneo, uma vez que suscitou o processo de conscientização pública sobre os desequilíbrios ecológicos causados pelas atividades humanas. A obra teve grande repercussão política e cultural, pois questionou a confiança e a credibilidade do progresso tecnológico, alertando sobre os problemas ambientais decorrentes do uso de pesticidas sintéticos - principalmente o DDT. Em 1968, Garret Gardin publicou um artigo, no qual discutiu a possibilidade de exaustão ou degradação massiva dos recursos comuns, frente ao crescimento populacional e ao gerenciamento inadequado do uso dos recursos naturais. Ambas as contribuições supracitadas foram bastante criticadas e desacreditadas em um primeiro momento. Porém, atingiram o seu objetivo principal ao alertar e conscientizar a população sobre a questão ambiental.

Em 1968 foi fundada por cientistas, industriais e políticos a organização chamada Clube de Roma, que ficou conhecida internacionalmente em 1972 por meio da publicação do Relatório Meadows. A referida publicação comprovou cientificamente e disseminou a ideia de que o modelo de desenvolvimento econômico mundial é ecologicamente insustentável (MEADOWS, 1973).

Para Trevisol (2003), o Relatório Meadows influenciou profundamente as discussões sobre a problemática ambiental, sobretudo, na Conferência de Estocolmo em 1972. Por consequência, houve a confrontação de dois grupos distintos: o grupo de ativistas ambientais e o grupo daqueles que mantinham uma posição estritamente favorável ao crescimento econômico.

Antes disso, Zilberman (1997) também fez menção à formação e confrontação de dois grupos em especial: os ambientalistas, com foco somente no ambiente em detrimento da população; e os desenvolvimentistas, que acreditavam na busca incondicional pelo progresso e pelo bem estar social e econômico em detrimento do meio ambiente. Esse autor salientou que ambas as abordagens de visões bastante extremadas tratavam a questão ambiental de forma muito limitada, certamente pela ausência de conhecimento científico em profundidade, visto que a ciência ambiental ainda estava na sua infância.

A globalização da degradação socioambiental exigiu do meio científico, gradativamente, a internalização de valores e princípios ecológicos que assegurassem a sustentabilidade do processo de desenvolvimento. Emergiram novos enfoques metodológicos na tentativa de tratar da complexidade de tal problemática, tendo em vista a causalidade múltipla e o potencial sinergético dos processos de ordem física, biológica, tecnológica e social que a constituem (LEFF, 2001).

Segundo Bursztyn (2004), verificou-se que as universidades reproduzem uma tendência similar ao mundo das políticas públicas: quando algo novo e relevante emerge em um determinado contexto, logo se propaga; toma notoriedade pública. Então, diante dos questionamentos relativos à 
problemática socioambiental, sobretudo, aos alertas de explosão demográfica e aos efeitos da poluição industrial, o meio científico se mobilizou para estudá-la e tentar compreendê-la.

Consequentemente surgiram espaços voltados para a pesquisa e formação ambiental: “[...] como reflexo da demanda por soluções científicas e técnicas aos novos desafios identificados, alguns campos das ciências se mobilizaram" (BURSZTYN, 2004, p. 68).

No que diz respeito à inserção da temática ambiental nas instituições de ensino, Leal Filho (1999) comentou sobre a experiência das universidades européias. Segundo o autor, na Inglaterra, graus acadêmicos em ciências ambientais já eram oferecidos desde a década de 1970. Igualmente, na Alemanha, onde há uma tradição na abordagem técnica sobre temas ambientais, o assunto faz parte do cotidiano acadêmico há bastante tempo. Diferentemente das universidades inglesas, no entanto, onde são formados cientistas ambientais com uma visão mais global de meio ambiente, o ensino universitário alemão é orientado no sentido de formar técnicos altamente qualificados em áreas muito específicas.

O aumento da demanda por cursos universitários voltados para a questão ambiental na Inglaterra se dá na década de 1990, mesmo período em que os cursos abriram no Brasil. Em 1988 foram registrados 48 cursos ingleses voltados para o meio ambiente e em 1992 já havia 106 em funcionamento. A engenharia ambiental evoluiu de cinco para 12 cursos ao longo desse período na Inglaterra (CAWSEY, 1994; LEAL FILHO, 1999).

De acordo com Reis et al. (2005), no caso das universidades brasileiras, a questão ambiental também já era abordada há alguns anos. O processo de internalização se acentuou na década de 1970, e especialmente na década 1980, visto que neste período tal temática adquiriu importância e divulgação crescentes em razão dos acidentes ambientais e, sobretudo, pelas suas implicações sociais e econômicas. Bursztyn (2004) situou a vinculação dos temas ambientais como foco de interesse das pesquisas universitárias brasileiras, a partir da década de 1980.

Inicialmente se trabalhou através de disciplinas isoladas dentro da grade curricular dos cursos tradicionais de graduação, como engenharia civil, biologia e geografia. Destaca-se, no que se refere ao enfoque integrado e multidisciplinar, que o curso de ecologia com tal habilitação é o mais antigo, criado ainda na década de 1970 no Instituto de Biociências da UNESP. Posteriormente, surgiu o curso de engenharia sanitária, como sugestão da Política Nacional de Meio Ambiente (1981) e do Plano Nacional de Saneamento (1971), com a finalidade de tratar das questões mais ligadas ao saneamento básico, dado o acelerado processo de urbanização e desenvolvimento no qual o país se encontrava. Nas décadas de 1980 e 1990 o adjetivo ambiental também foi incorporado à engenharia sanitária.

Porém, frente às dificuldades observadas em muitos cursos tradicionais de graduação, em função da departamentalização e fragmentação do conhecimento sobre a questão ambiental, verificou-se a necessidade de melhorias na capacitação oferecida até as décadas de 1980 e 1990 pelas instituições de ensino superior (REIS et al., 2005). A partir de uma abordagem mais integrada e sistemática na preparação de profissionais para o atendimento da demanda ambiental e das exigências do mercado nessa área, gradativamente, o adjetivo ambiental foi sendo acoplado às diversas disciplinas: economia ambiental, engenharia ambiental, direito ambiental, educação ambiental, sociologia ambiental, história ambiental, geologia, química, além de outras variações, como agroecologia.

Neste sentido, Leal Filho (1999) colocou que na década de 1990 houve uma difusão de cursos sequenciais, tecnológicos e de graduação ligados à temática ambiental, com as mais variadas denominações. Reis et al. (2005) corroboram, afirmando que nesse período observou-se uma verdadeira explosão dos cursos de graduação voltados para o meio ambiente no país. Assim sendo, conclui-se que na década de 1990, tanto na Inglaterra (CAWSEY, 1994), quanto no Brasil (LEAL FILHO, 1999; REIS et al., 2005), houve maior abertura de cursos universitários na área ambiental. 
Leal Filho (1999) comentou sobre os elementos que justificaram a criação de cursos no âmbito das ciências ambientais e citou de modo geral como incentivadores: a realidade de mercado, a complexidade do tema, a evolução tecnológica, a legislação e a dinâmica de ensino.

Ainda embasado em Leal Filho (1999) e, portanto, no contexto da década de 1990, previu-se a importância de algumas áreas, cujos profissionais pudessem contribuir na direção de um futuro mais sustentável para o Brasil. Foram citados pelo autor os seguintes campos: tecnologia ambiental, direito ambiental, informática ambiental, política ambiental, manejo e planejamento ambiental, educação e informação ambiental, saúde ambiental e consultoria ambiental.

No que se refere à realização de pesquisas na área de meio ambiente, Bursztyn (2004) relatou que a base de dados mais antiga no Brasil se chama SELAP - Sistema em Linha de Acompanhamento de Projetos - do Conselho Nacional de Desenvolvimento Científico e Tecnológico $(\mathrm{CNPq})$, cuja última atualização foi feita em 1985. Na época haviam cadastrados no sistema, 54 mil pesquisadores vinculados a 36 mil projetos em diversas áreas.

Nesse sentido, considerando a totalidade dos projetos desenvolvidos no país até 1985, somente 580 se identificavam com a categoria Meio Ambiente e Recursos Naturais. Quanto ao número de pesquisadores da referida área, dos 54 mil, somente 2 mil se dedicavam à temática ambiental. Portanto, no período considerado, a pesquisa ambiental representava somente 1,60\% de todas as linhas pesquisadas e era objeto de estudo de $3,78 \%$ dos pesquisadores cadastrados (BURSZTYN, 2004).

Segundo dados do SELAP, as linhas mais pesquisadas até a década de 1980 foram: recursos naturais $(23,97 \%)$, poluição $(21,21 \%)$ e estado ambiental (15\%). Percebe-se que a linha relacionada à educação ambiental ocupa a última posição (1,38\%). De modo geral, Bursztyn (2004) avaliou que a concentração da pesquisa ambiental se dá nas áreas da engenharia, sobretudo a sanitária, na biologia e na química. As áreas relativas à economia, sociologia e política não aparecem nas estatísticas até o referido período.

Em 1999 foi criada pela Coordenação de Aperfeiçoamento de Pessoal de Nível Superior (CAPES) a área multidisciplinar, hoje denominada interdisciplinar. Desde a sua criação é a área da pós-graduação brasileira que mais cresce, tanto por meio de cursos profissionalizantes, quanto acadêmicos, destacando inclusive, sua inserção em regiões menos favorecidas, como o norte e nordeste. Esse crescimento acompanha uma tendência mundial de aumento de grupos de pesquisa e programas acadêmicos com foco em questões complexas, como é a questão ambiental (CAPES, 2013).

Cronologicamente, Bursztyn (2004) constatou que a distribuição do número de pesquisas na área ambiental em 2003 era bem mais equitativa, comparativamente ao ano de 1985, de modo que a interface com a área de humanidades começa a ter uma representatividade maior. Percebe-se a inserção da pesquisa ambiental na área das ciências sociais aplicadas e nas ciências humanas. As engenharias contribuem pouco, mas não menos que as ciências da saúde.

Reis et al. (2005) apresentaram o número de cursos do ensino superior com interface em meio ambiente cadastrado junto ao banco de dados do MEC em 2004, entre graduação, tecnológicos e sequenciais. Registrou-se um total de 284 cursos com nomenclaturas bastante diversificadas.

Quantitativamente, a área das engenharias, sobretudo, a engenharia ambiental com 67 registros, é a mais expressiva no referido período. A engenharia sanitária e ambiental e a engenharia sanitária se igualam com poucos cursos no país com somente cinco registros. Ressalta-se também a representatividade, entre os cursos tecnológicos, do curso de gestão ambiental com o registro de 47 cursos no país no referido período.

Em 2004, encontravam-se em funcionamento 284 cursos, entre graduação, tecnológicos e sequenciais. Passados dez anos, registrou-se um total de 702 cursos presenciais em atividade nas três modalidades, credenciados pelo Ministério da Educação (MEC). Relacionada, particularmente, aos cursos de graduação, de 161 cursos em 2004, observou-se uma elevação para 351 em 2013 
(REIS et al., 2005; BRASIL, 2014). Em suma, a Tabela 1 apresenta a evolução do número de cursos na área de meio ambiente nos anos de 2004, 2011 e 2013:

Tabela 1 - Evolução do número de cursos de nível superior com interface em meio ambiente nos anos de 2004, 2011 e 2014. Fontes: (REIS et al., 2005; SOUZA, 2012; BRASIL, 2014).

\begin{tabular}{lccc}
\hline & $\mathbf{2 0 0 4}$ & $\mathbf{2 0 1 1}$ & $\mathbf{2 0 1 3}$ \\
\hline Graduação & 161 & 296 & 351 \\
Tecnológicos & 107 & 306 & 313 \\
Sequenciais & 16 & 8 & 8 \\
\hline Total & $\mathbf{2 8 4}$ & $\mathbf{6 1 0}$ & $\mathbf{7 0 2}$ \\
\hline
\end{tabular}

Assim como na análise de Reis et al. (2005) corroborada por Souza (2012), verificou-se que as engenharias em suas diversas modalidades permanecem como a área de maior expressividade. Enquanto em 2004, contudo, a engenharia ambiental (67) apresentava o maior número de cursos, observou-se que atualmente a engenharia ambiental e sanitária (161) se encontra em números mais significativos.

Comparativamente, verifica-se que em 2004 havia apenas quatro modalidades de engenharia tratando de meio ambiente (REIS et al., 2005). Em contrapartida, em 2011 (SOUZA, 2012), percebe-se a existência de 12 nomenclaturas diferentes que correspondem a 255 cursos de graduação, conforme apresenta a Tabela 2.

Tabela 2 - Distribuição do número de cursos de graduação com interface em meio ambiente em 2011. Fonte: (SOUZA, 2012).

\begin{tabular}{lc}
\hline \multicolumn{1}{c}{ Curso } & Quantidade \\
\hline Engenharia Agrícola e Ambiental & 10 \\
Engenharia com habilitação em Engenharia Ambiental e Sanitária & 5 \\
Engenharia Ambiental & 61 \\
Engenharia Ambiental e Energias Renováveis & 3 \\
Engenharia Ambiental e Sanitária & 161 \\
Engenharia Ambiental e Sanitária com habilitação em Eng. Ambiental e Sanitária & 2 \\
Engenharia Ambiental e Urbana & 1 \\
Engenharia Civil e Ambiental & 2 \\
Engenharia de Minas e Meio Ambiente & 1 \\
Engenharia de Produção - Meio Ambiente & 1 \\
Engenharia de Recursos Hídricos e do Meio Ambiente & 1 \\
Engenharia Sanitária e Ambiental & 7 \\
\hline Total & $\mathbf{2 5 5}$ \\
\hline
\end{tabular}

Além das engenharias mais consolidadas - engenharia ambiental, engenharia ambiental e sanitária e engenharia sanitária e ambiental - há interface com a área agrícola, civil, de minas, recursos renováveis, recursos hídricos, urbana e de produção.

\section{A EMERGÊNCIA DA ENGENHARIA AMBIENTAL, FACE À BUSCA PELA SUSTENTABILIDADE}

Zilberman (1997) colocou que a ciência ambiental na qual se insere a engenharia ambiental baseia-se na integração entre algumas linhas de pesquisa consideradas relevantes, que se desenvolvem em torno de temas-chaves, tais como: perspectiva global, poluição, sustentabilidade, o meio urbano, valores, ética, justiça social, entre outros. Trata-se de uma área cuja emergência abriu 
novos horizontes para a compreensão das relações entre as ciências biológicas e físicas; e que, portanto, requer uma cooperação interdisciplinar. Dessa forma, o principal objetivo desta ciência consiste na obtenção de conhecimentos básicos para compreender sistematicamente como o planeta funciona, tendo em vista a complexidade dos problemas ambientais e seus efeitos globais.

De acordo com Leal Filho (1999), as ciências ambientais procuram compreender os mecanismos através dos quais os problemas ambientais podem ser resolvidos, levando em consideração os aspectos ecológicos, sociais, políticos e econômicos. O autor acredita que é a abordagem mais sincronizada com as necessidades do mundo moderno, onde o desenvolvimento tecnológico acelerado também exige velocidade e eficiência na busca por soluções mais holísticas para os problemas ambientais.

Da mesma forma, para Trevisol (2003), o envolvimento dos cientistas nesse debate e o gradativo surgimento das ciências ambientais vêm contribuindo para revelar os diferentes ângulos da crise ecológica, uma vez que cabe à ciência direcionar esforços para sua compreensão e, sobretudo, na investigação de seus efeitos sobre o homem e ao ambiente.

Rodrigues (2004) discutiu sobre a evolução da engenharia do ambiente na Europa e afirmou que o curso surgiu em Portugal, no início da década de 1980, pela ação de profissionais da área e pela consequente relevância social, econômica e científica no contexto da sociedade portuguesa. $\mathrm{O}$ autor coloca que essa área derivou de uma expansão ou especialização da engenharia civil. Deste modo, a maioria dos cursos universitários de engenharia de meio ambiente, tanto portugueses, quanto ingleses, irlandeses ou espanhóis, mantém um forte componente da engenharia civil ou sanitária na sua formação acadêmica.

$\mathrm{Na}$ América Latina, mais precisamente na Colômbia, o curso foi inserido através da Universidad de los Andes, ainda em 1970, data anterior ao relatado por Rodrigues (2004) em Portugal. Foram criados dois cursos na referida universidade: um de caráter mais geral denominado "Ingeniería Ambiental I", e outro mais específico orientado para soluções de engenharia para os problemas ambientais, integrado ao curso de engenharia civil e denominado "Ingeniería Ambiental II" (DURÁN, 2007).

No Brasil, o curso de engenharia ambiental surgiu a partir da perda de espaço da engenharia sanitária, cujo foco era essencialmente em recursos hídricos e uma estreita ligação com a engenharia civil. A partir da percepção da complexidade da problemática ambiental, da ocorrência de eventos extremamente impactantes, bem como, da insuficiência de disciplinas que tratassem da temática com uma abordagem multidisciplinar, não contemplada pelos cursos tradicionais até o momento, pensou-se na criação de uma nova área do conhecimento científico para o atendimento de uma demanda crescente. É neste contexto que se justifica a criação do curso de engenharia ambiental.

Para Rosso et al. (1999), havia carência de um profissional capacitado para encontrar soluções tecnológicas apropriadas; que atendessem as transformações e necessidades humanas - $\mathrm{o}$ que afinal, é o papel do engenheiro de modo geral -, mas que simultaneamente pudesse salvaguardar a conservação do meio ambiente. E a finalidade da engenharia ambiental, segundo esses autores, é justamente esta: fazer uso da inovação tecnológica, tendo em vista um planejamento integrado do uso dos recursos naturais sem comprometer as características ecológicas do meio. A necessidade da área da engenheira ambiental se dá, portanto, como forma de minimizar os impactos causados pelo homem à natureza.

Logo, com o objetivo de suprir a lacuna existente no ensino da engenharia para uma demanda real de mercado, o Ministério da Educação (MEC) regulamentou em 1994, por meio da Portaria n. 1.693, a criação de uma nova habilitação denominada engenharia ambiental, definindo as matérias de formação básica e formação profissional geral (BRASIL, 1994). O reconhecimento, enquanto profissão, pelo órgão de classe da engenharia se dá em 2000 - Resolução CONFEA n. 447 (CONFEA, 2000). 
As diretrizes curriculares do curso de engenharia, de modo geral, são determinadas pela Resolução do Conselho Nacional de Educação, da Câmara de Educação Superior (CNE/CES) n. 11 de 2002 (BRASIL, 2002a). O egresso em engenharia, de acordo com o art. 3, caracteriza-se por um profissional de formação generalista, humanista crítica e reflexiva, com capacidade para absorver e desenvolver novas tecnologias, identificando e resolvendo problemas ambientais, tendo em vista os aspectos políticos, econômicos, sociais, ambientais e culturais, em atendimento às demandas da sociedade.

Rodrigues (2004), a partir da experiência do curso de engenharia ambiental em Portugal, reiterou que os problemas ambientais são bastante complexos e os engenheiros ambientais enfrentam desafios cada vez mais difíceis na tentativa de resolvê-los ou minimizá-los. Neste sentido, esse autor pontuou como norteadores da formação do profissional da engenharia ambiental português, três componentes: o científico, o tecnológico e o social.

No que diz respeito ao perfil acadêmico do engenheiro ambiental, a Portaria MEC n. 1.693, de 1994, art. 6, prevê a matéria de biologia como formação básica; e com relação às matérias de formação profissional geral; citam-se: geologia, climatologia, hidrologia, ecologia geral e aplicada, hidráulica, cartografia, recursos naturais, poluição ambiental, impactos ambientais, sistemas de tratamento de água e de resíduos, legislação e direito ambiental, saúde ambiental, planejamento ambiental e sistemas hidráulicos e sanitários (BRASIL, 1994).

Relacionado aos temas abordados na formação do egresso em engenharia ambiental, constam, nas Referências Nacionais do Curso de Engenharia Ambiental (BRASIL, 2002b), outros conteúdos: microbiologia, pedologia, fotogrametria, informática, geoprocessamento, mecânica dos sólidos, mecânica dos fluídos, gestão ambiental, hidráulica ambiental e recursos hídricos, avaliação de impactos e riscos ambientais, caracterização e tratamento de resíduos sólidos, líquidos e gasosos, ciência dos materiais, ergonomia e segurança do trabalho, métodos numéricos, modelagem ambiental, análise e simulação de sistemas ambientais e sistemas de informação.

Rodrigues (2004) também mencionou algumas disciplinas que fazem parte dos currículos dos cursos de engenharia de meio ambiente tanto na Europa, quanto nos currículos norte e sulamericanos: economia ambiental, geologia ambiental, energia ambiental, ambiente atmosférico, gestão ambiental, sociologia ambiental, entre outras áreas do conhecimento associadas à temática. Para o autor, é necessário que o engenheiro ambiental tenha um profundo conhecimento das áreas científicas básicas tradicionais, como matemática, física e química e ainda, que faça parte de seu currículo, conteúdos na área de biologia, geologia e economia.

No Brasil, o primeiro curso superior de engenharia ambiental entrou em funcionamento por intermédio da Universidade Federal do Tocantins (UFT) somente em 1992. Em seguida, embora criado em 1991, o curso teve seu início pela Universidade Luterana do Brasil (ULBRA) no ano de 1994, em Canoas, Rio Grande do Sul.

Quanto às atividades que podem ser desempenhadas, cita-se: o monitoramento das águas e do ar, fiscalização e assessoria ambiental de indústrias e empresas, execução e implantação de projetos sustentáveis, gestão ambiental, recuperação de áreas degradadas, geoprocessamento, pesquisas e estudos de impacto ambiental. A atuação do engenheiro ambiental está atrelada à preservação dos recursos hídricos, do ar e do solo; e no âmbito das empresas e dos processos produtivos, este profissional busca por processos ambientalmente mais sustentáveis.

Qualquer que seja a possibilidade de atuação, o desafio designado à engenharia ambiental, enquanto área emergente e em tempos de crise, exige o enfrentamento de preceitos antigos assumidos pela própria engenharia, no que diz respeito ao desenvolvimento de tecnologias e à necessidade de uma visão holística. A engenharia de modo geral encontra-se incondicionalmente atrelada à intervenção e transformação do meio natural, bem como, à produção de bens e serviços, através da realização e implementação de projetos com a finalidade de atendimento das necessidades humanas. 
Braga et al. (2002) destacaram a necessidade de focar, de modo sistemático, na questão da tecnologia apropriada para o desenvolvimento, levando em consideração a conservação ambiental e conciliando da melhor forma possível os aspectos socioeconômicos e ambientais. As palavras de Natal et al. (2005, p. 83) também são bastante esclarecedoras nesse sentido:

\footnotetext{
"A engenharia ambiental é uma ciência criativa. Lamentavelmente, em muitos projetos dessa área não são levados em consideração os princípios ecológicos. Desde grandes obras, como a construção de açudes para abastecimento de água de megalópoles, a pequenas soluções, como a implantação de uma miniusina de compostagem de lixo para atender a uma pequena comunidade rural, há de se considerar, além dos fatores econômicos como a relação custo-benefício, também os possíveis impactos sob o ambiente e sob o meio social."
}

Mota (1997) também defendeu a ideia de que os engenheiros e profissionais de áreas correlatas devem desenvolver suas atividades de forma tal que causem o mínimo possível de impactos sobre os recursos naturais, afinal, "[...] a engenharia pode e deve exercer a sua função de utilizar e modificar os recursos ambientais, em benefício da humanidade, sem, contudo, provocar mudanças que tragam prejuízos ao próprio homem e ao meio".

No que se refere aos conceitos mais usualmente associados à engenharia ambiental, as tecnologias ambientais consideram somente o controle da poluição, medidas técnicas e uma abordagem simples de atuação, na qual se observa o aumento de custos e o tratamento pontual dos problemas ambientais. Em contrapartida, o emprego de tecnologias limpas tem como objetivo a minimização e a prevenção de riscos para o meio ambiente e para a saúde humana, por meio de uma abordagem integrada. O paradigma da sustentabilidade adota medidas técnicas e não técnicas através de uma atuação voltada para a prevenção da poluição e uma abordagem integrada (GUTIERREZ-MARTIN e HÜTTENHAIM, 2003).

Logo, em detrimento de uma abordagem reducionista, simples, caracterizada pela ausência, deficiência ou desconsideração de conhecimentos sobre o funcionamento do meio ambiente, bem como, pela adoção de medidas pontuais, corretivas e pouco efetivas, o caminho a ser seguido deve oferecer, potencialmente, alternativas duradouras e melhor sucedidas em busca da sustentabilidade.

\section{CONSIDERAÇÕES FINAIS}

A criação de cursos na área de meio ambiente, com as mais variadas titulações e modalidades, é reflexo da necessidade cada vez mais urgente de tratar os problemas de ordem ambiental. No entanto, soluções efetivas dependem de ações sistemáticas, derivadas de uma abordagem integrada e multidisciplinar. A simples adoção de tecnologias ambientais implica em medidas puramente técnicas e corretivas, que são necessárias, mas não suficientes para lidar com a complexidade que a temática ambiental exige.

Logo, embora se tenha uma variedade de cursos na área ambiental em todo o país, com grades curriculares diferenciadas, a formação de recursos humanos para o trato desse tema pelas universidades deve ultrapassar a simples criação de um espaço acadêmico constituído pela integração ou homogeneização de disciplinas tradicionais. O ideal é que os cursos que capacitam educadores ambientais incorporem a percepção integrada da natureza e fomentem uma participação crítica e responsável na solução de problemas ambientais.

A evolução do número de cursos na área de meio ambiente, apresentada no artigo por meio de consulta em pesquisas anteriores e atualizadas no banco de dados do INEP, é reflexo justamente do aumento da demanda por profissionais desta área. Entre 2004 e 2013 verificou-se um aumento bastante expressivo de 284 para 702 cursos ligados à temática ambiental, nos níveis de graduação, tecnológicos e sequenciais. Especificamente sobre a interface entre a engenharia e o meio ambiente, tem-se um registro de 255 cursos com 12 titulações diferentes. O mercado de atuação desses 
profissionais está atrelado à ocorrência de impactos ambientais, que por sua vez derivam de toda e qualquer atividade que interfira sobre os processos ecológicos. Assim, trata-se, indubitavelmente, de uma demanda em constante ascensão.

A engenharia voltada para o meio ambiente também deve proporcionar a contínua evolução tecnológica, desde que baseada em princípios de gestão integrada e por consequência, que proponha alternativas mais sustentáveis. Diferentemente das outras engenharias, o aspecto social é fortemente destacado na formação do egresso em engenharia ambiental, reconhecendo seu caráter multidisciplinar e atentando para a preocupação com a compreensão da dicotomia homem-ambiente ou sociedade-natureza.

\section{REFERÊNCIAS}

BRAGA, B; HESPANHOL, I; CONEJO, J. G. L; MIERZWA, J. C; BARROS, M. T. L. de; SPENCER, M; PORTO, M; NUCCI, N; JULIANO, N; EIGER, S. Introdução à engenharia ambiental. São Paulo: Prentice Hall, 2002. 318p.

BRASIL. Conselho Nacional de Educação (CNE)/Câmara de Educação Superior (CES). Resolução n. 11 de março de 2002a. Institui diretrizes curriculares nacionais do curso de graduação em engenharia.

BRASIL. Lei n. 9.605 de 12 de fevereiro de 1998 (Lei de Crimes Ambientais). Dispõe sobre as sanções penais e administrativas derivadas de condutas e atividades lesivas ao meio ambiente, dá outras providências.

BRASIL. Ministério da Educação. Portaria n. 1693 de 5 de dezembro de 1994. Cria a área da engenharia ambiental.

BRASIL. Ministério da Educação/Instituto Nacional de Estudos e Pesquisas Educacionais Anísio Teixeira (MEC/INEP). Instituições de ensino superior e cursos cadastrados: e-mec, 2014. Disponível em: <http://emec.mec.gov.br/>. Acesso em jan. 2014.

BRASIL. Ministério da Educação/Secretaria de Educação Superior. Referenciais Nacionais dos Cursos de Engenharia. Brasília, 2002b.

BURSZTYN, M. Interdisciplinaridade: é hora de institucionalizar! Ambiente \& Sociedade, Campinas, v. 2, n. 5, p. 229-231, jul./dez. 1999.

Meio ambiente e interdisciplinaridade: desafios ao mundo acadêmico.

Desenvolvimento e Meio Ambiente, n. 10, p. 67-76, jul./dez. 2004.

CAPES - COORDENAÇÃO DE APERFEIÇOAMENTO DE PESSOAL DE NÍVEL SUPERIOR. Documento de área 2013. Diretoria de Avaliação: avaliação trienal 2013.

CAWSEY, D.C. University Environmental Education: The Role of International Programmes. Marine Pollution Bulletin, v. 29, n. 6-12, 1994, p. 584-588.

CONFEA. Resolução n. 447 de setembro de 2000. Dispõe sobre o registro profissional do engenheiro ambiental e discrimina suas atividades. Disponível em:

<http://normativos.confea.org.br/downloads/0447-00.pdf>. Acesso em mai. 2013. 
DURÁN, G.G. Surgimiento y evolución de la Ingeniería Ambiental em Colombia. Revista de Ingeniería, Universidad de los Andes, 2003. p. 122-130.

GUTIERREZ-MARTIN, F; HÜTTENHAIM, S.H. Environmental education: new paradigms and engineering syllabus. Journal of Cleaner Production, v. 11, p. 247-251. 2003.

HARDIN, G. The Tragedy of the Commons. Science, New Series, v. 162, n. 3859, dez. 1968, p. 1243-1248.

LEAL FILHO, W. Meio ambiente: um tema de valor estratégico para a universidade brasileira. Ambiente \& Sociedade. Ano 2, n. 5, p. 191-201, 2. sem.1999.

LEFF, E. Saber ambiental: sustentabilidade, racionalidade, complexidade, poder. Petrópolis, RJ: Vozes, 2001. 343 p.

MEADOWS, D.H. Limites do crescimento: um relatório para o projeto do Clube de Roma sobre o dilema da humanidade. São Paulo: Perspectiva, 1973. 200 p.

MOTA, S. Introdução à engenharia ambiental. Rio de Janeiro: ABES, 1997. 280 p.

NATAL, D; MENEZES, R.M.T. de; MUCCI, J.L.N. Fundamentos de Ecologia Humana. In: PHILIPPI Jr., A; PELICIONI, M. C. F. Saneamento, saúde e meio ambiente. Barueri, SP: Manole, 2005. p. 57-86.

REIS, F.A.G.V; GIORDANO, L. do C; CERRI, L. E. S. Contextualização dos cursos superiores de meio ambiente no Brasil: engenharia ambiental, engenharia sanitária, ecologia, tecnólogos e sequenciais. Eng. Ambient. Espírito Santo do Pinhal, v. 2, n. 1, p. 5-34, jan./dez. 2005.

RODRIGUES, A.F.F. Evolução da engenharia do ambiente em Portugal e na Europa. Eng. Ambient. Espírito Santo do Pinhal, v.1, n.1, p.11-16, jan./dez. 2004.

ROSSO, T.C.A; RITTER, E; TAVARES, B.M. Engenharia ambiental: perspectivas quanto à nova habilitação em engenharia. In: ASSOCIAÇÃO BRASILEIRA DE ENGENHARIA SANITÁRIA E AMBIENTAL, Rio de Janeiro, 22, 1999. p. 3050-3058. Anais eletrônicos...Disponível em: <http://www.bvsde.paho.org/bvsaidis/brasil20/viii-006.pdf>. Acesso em mai. 2014.

SOUZA, G.C. de. A emergência de novas áreas do conhecimento científico para a problemática socioambiental: o caso da engenharia ambiental e sua contribuição no contexto da Região Carbonífera Catarinense. Dissertação (Mestrado) - Universidade do Extremo Sul Catarinense, Programa de Pós-Graduação em Ciências Ambientais, Criciúma, 2012.

TREVISOL, J.V. A educação ambiental em uma sociedade de risco: tarefas e desafios na construção da sustentabilidade. Joaçaba: UNOESC, 2003. 201p.

ZILBERMAN, I. Introdução à engenharia ambiental. Canoas, RS: ULBRA - Universidade Luterana do Brasil, 1997. 101p. 